\title{
The Origin and Evolution of Confucius Ceremony Musical Dance in China and South Korea
}

\author{
Lu Bai \\ African \& African American Studies \\ Duke University \\ Durham, United States
}

\begin{abstract}
Confucius Ceremony Musical Dance is one of the important rituals for Confucius Ceremony, which is called the "image" of Confucian ritual and music culture. Confucius Ceremony Musical Dance originated in China, inherited to South Korea. For more than two thousand years, Confucius Ceremony Musical Dance in China and South Korea have been closely linked with the fate of the country. It can be said that "If the country is prosperity then the Confucius Ceremony Musical Dance is prosperity, if the country is in bad condition, then it is in bad condition". Every time it comes to dynasty change, on one hand it will respect and follow along the ancient system, on the one hand it stressed that the music will not be the same, so the two countries' dance and music experienced ups and downs, now they all present their own characteristics.
\end{abstract}

Keywords-Confucius ceremony musical dance; Confucian Temple dance; China and South Korea; big dance of six generations ; Confucius Ceremony

\section{INTRODUCTION}

Confucius Ceremony Musical Dance is a dance performed at the memorial service of the Confucian masters headed by Confucius. It orig inated in ancient China and was introduced to South Korea during the Song Dynasty. As the founder of Confucianism, Confucius' ritual and music culture which is the core part of his ideology has always influenced the East and even the human civilization. The Confucius Ceremony Musical Dance is the artistic form of rites and music culture. The $\mathrm{Yi}, \mathrm{Ci}$, Qian thoughts contained in the dance movements can be regarded as the ritual attitudes that should be most valued among people in daily life. Today, China and South Korea follow the Spring and Autumn two ceremonies a year, in China it only apply Wen dance, South Korean apply both Wen and Wu two dances.

\section{ORIGIN OF THE CONFUCIUS CEREMONY MUSICAL DANCE}

\section{A. Origin of the Confucius Ceremony Musical Dance}

1) Witch culture: The original meaning of "witch" is "the one who destroys God by dancing." [1] That is to say, "witch" is an important connection media between man and God, "dance" is the most important part. When the ancestors express their prays and thanks to heaven, he would accomplish the purpose of entertaining God through ritual sacrifices, dances, vocals and other activities. Such a witchcraft ritual is the prototype of "ceremony," and the indispensable comprehensive artistic act in the ceremony song music dance, is the predecess or of "music". [2] During the Xia and Shang dynasties, the witch-government merged one after another, and the governor used the "witch" as their means of rule. After that, the ritual culture formed in Zhou dynasty was based on this.

2) Rites and music culture: To the Zhou dynasty, such witchcraft rituals with "witchcraft" color gradually developed into a kind of cultural system called "ceremony". The ceremonial dance in the ceremony is no longer limited to the scope of communication with the gods, but evolved into an important tool for ruler to teach their people, which is consistent as inseparable with the order of the superiority of the patriarchal system. The establishment of the patriarchal system directly affects the dance form while performing to the emperor, leud, senior official, and scholars, which is the number of the dance rows. For emperor is eight rows of dancers, for leud is six rows of dancers, for senior official is four rows of dancers, for scholars is two rows of dancers. [3] The ritual culture under patriarchal system is a strict observance of order, so the dance has also become a manifestation of its system.

3) Benevolent culture: In the late Western Zhou Dynasty, the rules and regulations of feudal system faced with collapse, as well as the rites and music culture, and the "benevolence" thought put forward by Confucius brought a new turning point for the ritual music culture under the feudal system. Under the proposition of Confucius' "Subdue oneself and return to the proprieties", the original ritual system for the purpose of entertaining God establishes a contact with moral cultivation, pays attention to the cultivation of personality and the ritual norms a mong people, tries to maintain the social order through the rites and music cultivation. The Confucius Ceremony Musical Dance we see today inherited such Confucius rites and music, which is cultivated with morality and music.

\section{B. The Big Dance of Six Generations}

The current dance at the ceremony is not exclusively made for the Confucius Ceremony. Its origins can be traced 
back to The big dance of six generations in ancient China, which are the "Yun Men Da Juan" in the Yellow Emperor period, the "Xianchi" in the Tang Yao Dynasty, "Da Shao" in Yu Shun Period, "Da Xia" in Xia Yu Period, "Da Tai" in Shang and Tang Dynasties and "Da Wu" in Zhou Wu Period. All these six dances are the dances celebrating the merit of contemporary emperors. In Zhou Dynasty they were collected together and widely used in various rituals in the Zhou dynasty. "Dong Han Hui Yao" recorded that after the death of Confucius, the Emperor Zhang of Han Dynasty sacrificed Confucius and his seventy-two disciples with the music of six generations [4]. Today, the six-dynasty dance, which has undergone thousands of years of dynastic change, is hardly survived. However, the tradition of remembering the first teacher Confucius has been preserved.

In the Ming Dynasty, Zhu Zaiyu's "Yue Lv Quan Shu. Spectrum of Six Generations Dance" has detailed description of the dance movements of six dances. Among the six dances only "Ren Wu" (another name of Xian chi) has pictures exist in "Yue Shu" which wrote by Chen Yang from Song Dynasty. According to this figure, Zhu Zaiyu made drawings of "Yun Men", "Da Shao", "Da Xia", "Da Tai" and "Da Wu" as in "Fig. 1" and "Fig. 2".

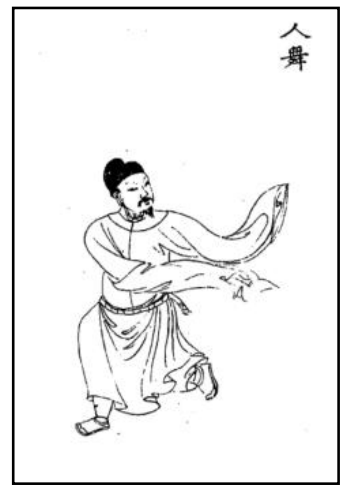

Fig. 1. "Ren Wu" in "Yue shu".

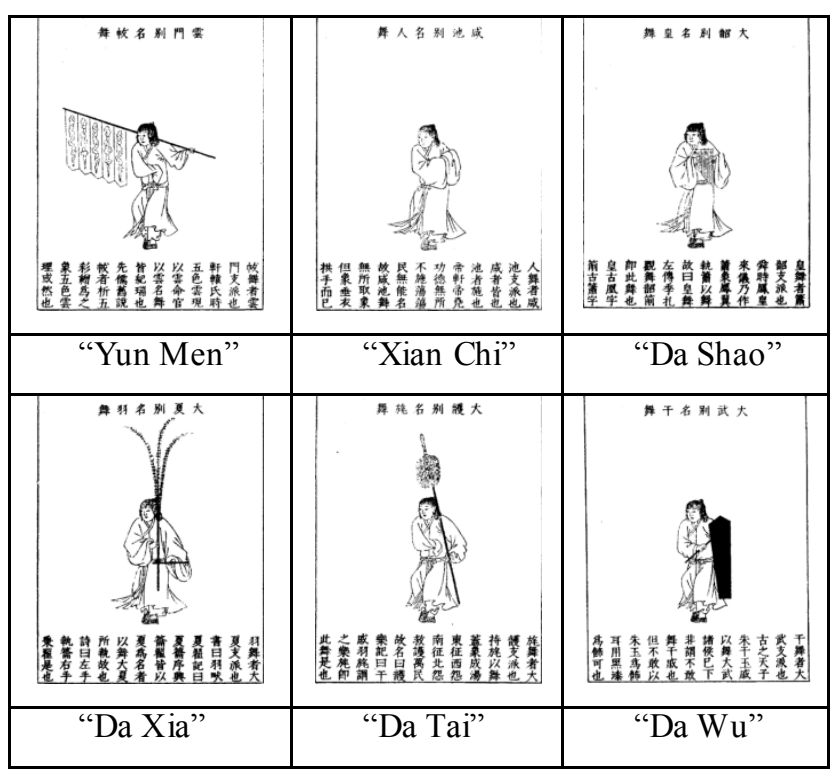

Fig. 2. The Big dance of six generations in "Yue Lv Quan Shu”.
It can be seen that the big dance of six generations in addition to "Xian Chi", others are all dances with tools. When perform "Yun Men" they use colorful silk, when perform "Xian Chi", they wave sleeves with bare hand, when perform "Da Shao" they hold Xiao with both hands, when perform "Da Xia" they hold Zhai and lun in hands, when perform "Da Tai" they use mao, when perform "Da Wu" they hold Gan jin right hand and hold Qi in right hand. Among them, "Xian Chi", "Da Shao", and "Da Xia" are Wen wu, "Yn Men", "Da Tai", "Da Wu" are Wu wu. Such sixdances are the one used in Confucius Ceremonies by the emperors.

\section{The Development of Confucius Ceremony Musical Dance}

After Confucius died, his disciples mourned him for three years, and $\mathrm{Lu} \mathrm{Ai} \mathrm{Gong} \mathrm{built} \mathrm{a} \mathrm{temple} \mathrm{in} \mathrm{his} \mathrm{old} \mathrm{house,}$ that is the earliest record of the Confucius Ceremony. Later, "in the 12th year of Han emperor period, he passed through Lu on his East patrol and held a Confucius Ceremony at Tai Lao.", [5] which created the history of Chinese emperors' Confucius Ceremony. However, judging from these records, whether the earliest ceremonies have performed dance we cannot know, until the "Dong Han Hui Yao" recorded " Emperor Zhang of Han 2nd years, he held Confucius Ceremony in winter when he passed by Luci, and the six generations dances were performed in the ceremony." As well as "Emperor Zhang and Emperor An all held Confucius Ceremony to sacrifice Confucius and performed six generations dances." [6] The content is used to confirm the fact that in Han Dynasty at least appeared two times ceremony which performed the six generations dance.

During the Yuan Jia period of Southern Song Dynasty, Pei Song proposed that in the sacrifice should perform musical dance with 6 rows of dancers. However, due to the lack of music, they were not pursued until the Yong-Ming 3rd year of Emperor Qi Wu period, according to Wang Jian's proposal, sacrifice applied with musical dance with 6 rows of dancers. [7]

To the Sui Dynasty, the traces of the Six generations big dance has not much left, only performed with "Wen wu", "Wu Wu" in a variety of rituals. [8] Wen $\mathrm{Wu}$ required 64 dancers, hold Lun in their left hands and Zhi in their right hands, each 12 people for $\mathrm{Ba}, \mathrm{Mao}$ and $\mathrm{Yu}, \mathrm{Wu}$ wu required 64 dancers, hold Gan in their left hands and Qi in their right hands. [9] It shows that although there is no six generations dance in Sui Dynasty, but in the "Wen wu" and "Wu Wu" still use the dance props of six generations big dance.

The first year of Renshou in Sui Dynasty, Emperor Wen confirmed "Cheng Xia" as the sacrifice music, and customized exclusive lyric for the sacrifice ceremony, but whether the Confucius Ceremony Musical Dance is also specialized at this time, it is to be investigated. After the founding of the Tang Dynasty, Confucius Ceremony "Followed the old system of Sui Dynasty", still use "Cheng Xia" as the sacrifice music. Zhenguan 21 years of Emperor Taizong in Tang Dynasty, Confucius Ceremony used 6 rows of dancers. [10] Xianqing three years of Emperor Gaozong 
(685), the emperor decided "The music of Wen Xuan Wang Temple should use Xuanhe dance." [11] During Kaiyuan years of Emperor Xuanzong, both 6 and 8 rows of dance all practiced. [12] It shows that in Tang dynasty the sacrifice normally use 6 rows dance.

Another noteworthy point is that Tang Dynasty has 4 dances in total, on one hand it followed Sui Dynasty's "Wen $\mathrm{wu}$ " and "Wu $\mathrm{Wu}$ ", on the other hand it created the court musical dance "Qin Wang Po Zhen Yue" (Wu wu) and "Gong Cheng Qing Shan Yue"(Wen wu). Both two dances have changed their names many times, Wu wu "Qin Wang Po Zhen Yue" also known as "Qi De Wu", "Jiang Gong" (Southern Han), "Xiang Cheng" (Later Zhou), Wen wu "Gong Cheng Qing Shan Yue" also known as "Jiu Gong Wu", "Guan Xiang" (Later Han ), "Chong De" (Later Zhou). [13]

The "Xuan De Sheng Wen Zhi Wu" and "Tian Xia Da Ding Zhi Wu" which were widely practiced in the Song Dynasty's sacrifice ceremonies are based on the two dances of Tang Dynasty. And later it has profound influence for later Ming Dynasty's Wen Qing temple dance notation.

\section{EST ABLISHMENT OF CONFUCIUS CEREMONY MUSICAL DANCE IN CHINA AND SOUTH KOREA}

Song Dynasty respected Confucianism, prepared elegant music, not only awarded "Da Cheng Sacred Music" in the sacrifice ceremony, but also set the detailed dance movement, refer ton the dance figure in Tang Dynasty. It is also during this period, that Song Huizong sent Dacheng Sacred music and ceremonial dance together to Korea Ruizong as the gift, Confucian Temple dance passed into Korea since then.

\section{A. China's Confucius Ceremony Musical Dance}

1) Song Dynasty: In Jianlong first year of Emperor Song Taizu period (960), he renamed later Zhou Dynasty's "Chong De" into "Wende", renamed "Xiang Cheng" into "Wu Gong". In Qiande 4th year of Song Taizu period (966), it changed "Wen De" as "Xuan De Sheng Wen", changed "Wu Gong" as "Tian Xia Da Ding". The revision of the dancers, movement, dance content and variables for these two dances also take the reference of Tang Taizong's dance figure.

In Chunhua $2^{\text {nd }}$ year of Song Taizong period (991), he changed the Wen wu "Xuan De Sheng Wen" into "Hua Cheng Tian Xia", and changed Wu wu "Tian Xia Da Ding" into "Wei Jia Hai Nei". In Yuanyou 4th year (1089), Song Zhezong ordered Music official Ye Fang to revise the dance content of these two dances, there are three changes in both Wen wu and $\mathrm{Wu} w u$, and each change include three yi, three qian and three ci. This kind of dance content passed to the Ming Dynasty, and laid the foundation for a series of Confucian Temple dance spectrum of Ming Dynasty.

2) Ming Dynasty: In Ming Hongwu years, because the Ming Taizu wanted to show "Conquer the world with moral", so $\mathrm{Wu}$ wu was no longer performed in sacrificial ceremony. Since then, until the late Qing Dynasty, Confucian Temple ceremony only left Wen wu. Ming Jingtai four years (1455), sacrifice ceremony performed Wen wu with 6 rows of dancers. To Chenghua Thirteen years (1477), begin to use 8 rows of dancer in sacrifice ceremony.[14] In Hongzhi years, Confucius Ceremony Musial Dance get the re-attention. In Hongzhi 9th year (1496), the Confucius Ceremony Musical Dance was added to 70 dancers, like the emperor system. [15] It is at this time that the earliest literary scripture "Que Li Zhi" (1504) was compiled. In November of Jiajing nine years (1530), to it correct Confucius ceremony, use 6 rows dance. [16]

During the Ming dynasty, although the scale of Confucius Ceremony Musical Dance was changed, the publication and distribution of a series of dance notations laid a solid foundation for the rehabilitation work of the Confucius Ceremony Musical Dance in China and South Korea. The published dance notations in Ming dynasty were as follows: "Que Li Zhi” (1504), "Nan Yong Zhi”(1544), “Huang Zu Tai Xue Zhi”(1557), "Kong Sheng Quan Shu” (1585), "Sancai Tu Hui" (1597),"Pan Gong Li Yue Shu" (1573-1615).

3) Qing Dynasty: Because of the political and military needs, the Qing dynasty vigorously respected the Confucianis $m$ and Confucian culture, and at the same time also attached great importance to the revision of Confucius Ceremony Musial Dance. In the Ming Dynasty, there were "Xuan Ping Zhi Wu", "Zhi Ping Zhi Wu" and "Xu Ping Zhi Wu" which created on the basis of the original Ming Dynasty's Confucius Ceremony Musical Dance. [17] And there are changes in terms of action and dance props.

In Shunzhi 13th year (1656), revision of Ming Dynasty's music has performed and issued, For Welcome God and First Sacrifice play "Ning Ping", Second Sacrifice play "An Ping", Final Sacrifice play "Jing Ping", dance 6 rows, all three sacrifices perform Wen wu. In Kang xi 6th year (1667), formulated the "Zhong He Shao Yue" for the Confucius Ceremony in Imperial College. Kang xi Fifty-five years (1716) issued it to all provincial Confucius temples to use. During the reign of Emperor Qianlong, there are twice revisions of Confucius Ceremony Musical Dance. The first time revision is Qianlong's six years (1741), the revision was based on the music of Shunzhi period, the music and dance movements of national and provincial dance during this period were all included in "Lv Lv Zheng Yi". The second time revision is in Qianlong eight years (1743), dance for first sacrifice is "Xuanping Zhi Wu", dance for second sacrifice is "Zhi Ping Zhi Wu", dance for final sacrifice is "Xu ping zhi wu". Later in Guang xu thirty-two years (1906) the Confucius Ceremony was promoted to big sacrifice, dance with 8 rows and also add $\mathrm{Wu}$ wu. In this period, the Confucius Ceremony Musical Dance performed with the order of Wu wu for First sacrifice and Wen wu for second and final sacrifice. The dance movements are recorded in the "Dance notation of Confucius Ceremony "wrote by Zong Jiashu. 
In addition, a variety of dance notations were also published in the Qing Dynasty, including "Pan Gong Li Yue Quan Shu" (1656), "Dacheng Tongzhi" (1669), "Que li Guang Zhi" (1673), "Wen Miao Li Yue Kao" (1674), "Guo Xue Li Yue Lu" (1719), "Wen Miao Ding Ji Pu" (1845), "Qing Yi Pan Gong Yue Wu Tu Shuo" (1851), "Sheng Men Yue Zhi" (1887).

\section{B. Korean Confucian Temple Row Dance}

South Korea's Confucian Temple row dance was introduced in the Song Huizong period together with Da Cheng Sacred music, which is blended with local culture and formed its unique style. South Korea's Confucian Temple row dance experienced the establishment in Korai and Joseon Dynasty, the recession in Japanese occupied period, and the three times reproduction work in modern times, then was able to restore the ancient system, until today. South Korea is also the only country that maintains both $\mathrm{Wu}$ wu and Wen wu.

South Korea's Confucius Ceremony activities can be traced back to the Emperor Sosurim 2nd year of Koguryo (372), he performed the ceremony while established the Imperial Academy. After Chengzong 11th year (992), established Imperial College and Wen Xuan Wang Temple in Kai Jing; in Yi Zong 7th year (1112), the emperor personally joined in the sacrifice ceremony. [18]

1) Koryo period: In Ruizong 11th year (1116) years of Koryo, Song Huizong gave its Da Cheng Sacred music and the current row dance to them. Because Ruizong stressed that "both wen and wu should work together" so in South Korea's sacrifice it has maintained the tradition of both Wen wu and $\mathrm{Wu}$ wu performed together.

In the Yizong period, the 6 rows 36 dancers dance which were originally performed on a medium-scale ceremony, were revised into 6 rows 48 dancers. During Mingzong period, sacred music was once fallen into chaos. In order to restore the sacred music system, Mingzong once again sent envoys Xu Wen to Song Dynasty to learn, but at that time the once prevailed Da Cheng Sacred music in Song Dynasty was no longer popular, so it can be trusted. It is precisely because of the sacred music cannot be learned, so in Mingzong 18th year, there appeared a chaotic situation which sacred music and folk music performed together on stage.

During the period of Gongyongwang, Scared music was plunged into chaos once again, musicians dispersed and voices were lost. Gongyongwang also sent envoys Jiang Shizan to study in Ming Dynasty, try to restore scared music, but after all, he could not reach the prosperous scene of Ruizong period.

2) Joseon Dynasty: After experiencing the decline in late Goryeo Dynasty, the Confucian Temple row dancer ushered in a brand new change during the Joseon Dynasty. In the early days of Joseon Dynasty, there are many controversies over the placement of row dancers. Until the Sejong period, it correct the wrong placement of the row dance, and the dance was held "in the middle of temple" instead of north and south sides.

During the Joseon Jeongio period, it vigorously restore the ancient system include dance placement, dance movement, dance clothes and other aspects. The dance movement in this period was also included in the "Chun Guan Tong Kao" (1788), which has become the important historical data for restore of South Korea's Confucian temple row dance.

\section{THE CURRENT INHERIT ANCE SITUAT ION OF CONFUCIUS CEREMONY MUSICAL DANCE IN CHINA AND SOUTH KOREA}

The inheritance of Confucius Ceremony Musical Dance in China and South Korea passed until modern times and went ups and downs along with the political culture of the two countries. First of all, the dances in both two countries have been used by rulers. Secondly, both countries set up special educational institutions to inherit and restore ancient music while the musical dance is extinct. Finally, after experiencing distress and going through several rehabilitation activities, eventually presented the solemn ritual dance that we have seen today.

\section{A. Chinese Confucius Ceremony Musical Dance}

1) Confucius Ceremony Musical Dance in the Republic of China: In third year of the Republic of China (1914), Yuan Shikai issued the "Order of the Resumption of Confucian Ceremony" which set the two Ding days in Spring and Autumn as the Confucius Ceremony Day. Big ceremony will be performed and the sacrificial ceremony will be the same with "Heaven Sacrifice". On September 28th at the same year, the first Confucius Ceremony since the founding of the Republic of China has been held. However, history proves that the sacrificial activities in the Republic of China were merely tools for the governors to attempt to restore feudal rule. Although many ceremonies were held during the Republic of China, the record of Confucius Ceremony Musical Dance only appeared twice in "Fig. 3".

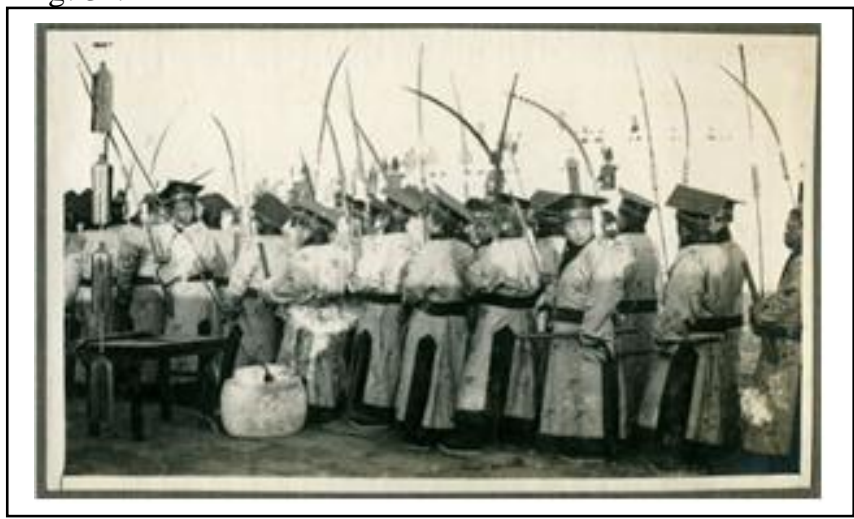

Fig. 3. Dancers for the Confucius Ceremony in 1915.

Another important act during the Republic of China was the establishment of the Ancient Music Institute during the 
Ten Years of the Republic of China (1912). Ancient Music Institute not only responsible for the cultivation of musical dancers during the Republic of China, but also provides an important clue for the documentary film of Confucius Ceremony Musical Dance in 1957.

2) Confucius Ceremony Row Dance after the founding of The People's Republic of China: After the founding of New China, the destiny of Confucius Ceremony Musical Dance together with Confucius Ceremony coincided with the restoration of the early days of the founding of New China, the suppression during the Cultural Revolution, and the preparedness in the 80 s until they prevailed in Confucius Temples throughout China in 2004.

In 1957, under the leadership of Wu Xiaobang, the Chairman of Chinese Dance Research Society, a documentary film entitled "Confucius Ceremony Musical Dance" started in Qufu. This image data is an important basis for the restoration work later. The filming dance moves are reproduced based on "Sheng Men Yue Zhi", which is the dance move after the revision at Emperor Qianlong 8th year (1743) of Qing Dynasty. After the restoration, Confucius Ceremony was never held again until the end of the Cultural Revolution in 1976 in "Fig, 4".

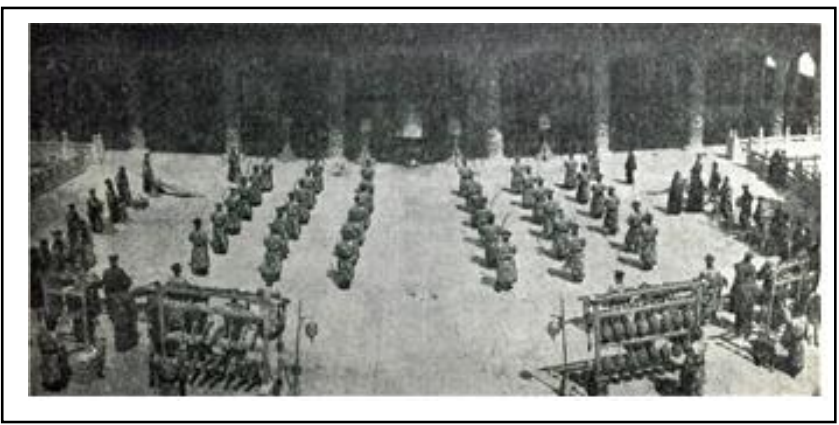

Fig. 4. Confucius Ceremony Musical Dance in 1957.

After the Cultural Revolution, Chinese sinology was rejuvenated and Confucius ceremony was also valued. In 1980s, Confucius Ceremony Musical Dance has been staged in Qufu for three times. First time in 1984, Jiang Fan, Ai Chunhua rehearsal the 4 rows "Que Li Gu Yue Wu"; Second time in 1985, performed Wen wu and 6 rows dance in front of Dacheng Hall; Third time in 1986, performed 8 rows dance by Shandong Bangzi theater in Qufu. During this period the restoration of dance movements are based on the dance notations from Qing Dynasty.

In 2004, Qufu Confucius ceremonies were divided into public sacrifices and family sacrifices, and the Confucius ceremony was also changed into Ming dynasty's system. The restoration of Confucius Ceremony Musical Dance based on the dance movements recorded in "Pan Gong Li Yue Shu" wrote by Li Zhizao from Ming Dynasty. After 2004, more than 20 local Confucian temples across the country set off a heat wave of Confucius Ceremony. A mong them, the places performed Confucius Ceremony Musical Dance include Nanjing, Hang zhou, Changchun, Harbin, Quzhou and Dujiangyan.

\section{B. Confucius Temple Row Dance in South Korea}

1) Confucian Temple row dance during the Japanese occupation period: During the Japanese occupation period, Confucian Temple row dance was forced to be abolished. Even if the Confucian ceremony was held, it would follow Japanese ceremony rite, the ancient system was all gone. The original 96 movements of Confucian Temple row dance only left the kowtowed movement toward north, east and west three directions, which is the row dance with the form of "three-direction kowtow". Such row dance without pitching and retreat, would lost the intrinsic meaning of wen and wu moral which symbolized by Confucian Temple row dance.

During the Japanese occupation period, the promotion of Confucian Temple sacrifice was in fact a means for Japanese imperialists to educate and rule Korea through ritual music. Nonetheless, in order to avoid the demise of sacred music, the establishment of the "The training institute of scared music" in 1919 was aimed at the training of sacred music students and row dance students, which played a positive role in the dance inheritance.

2) Confucian Temple row dance after the founding of the Republic of Korea: Since the founding of the Republic of Korea, the restoration of Confucian Temple row dance has also gone through several twists and turns. First is the confusing situation of the mixed word use of the ancestral temple dance and Confucian Temple row dance in 1949; Second is in 1980, under the leadership of Cheng Qinglin, although the row dance was reproduced, it was a huge difference between the dance notation; Final is in 2006, the research team of Koryo Songgyungwan Confucian Temple row dance which headed by Haksun-Lim, restored the Wen wu and $\mathrm{Wu}$ wu of Confucian Temple row dance on the bas is of the dance notation recorded in "Chun Guan Tong Kao" and "Yue Lv Quan Shu".

The restoration work in 1980 was held by National Traditional Music High School which led by Cheng qinglin. The person in charge said the restoration work was based on the "Pan Gong Li Yue Shu", but after research, the reference should be Zhang Anmao's "Pan Gong Li Yue Quan Shu" from the Qing Dynasty. This means that the restoration failed to complete by the reference of dance notation. And the movements of Wen wu and $\mathrm{Wu}$ wu were all the same, only changed the Lun and Zhai in Wen wu into Gan and Qin, thus the moral meaning was no longer exist. Such situation has lasted until 2006.

The restoration work of Confucian Temple dance in 2006 was started by the research team of Koryo Songgyungwan Confucian Temple row dance. After going through five academic rehearsals of the prototype restorationof the Confucian Temple dance, the row dance part of in the ceremony was staged by the 8 rows dance troupe of Sungkyunkwan University. The restoration work was based on the "Chun guan tong kao" (Wenwu) and "Yue Lv Quan Shu" (Wu Wu), restored Wenwu and Wuwu and at the same time. During the sacrifice ceremony, perform Wen 
wu for Welcome God, silk sacrifice, first sacrifice part, and perform $\mathrm{Wu} w \mathrm{w}$ for the second sacrifice and final sacrifice part.

\section{CONCLUSION}

From the above historical context of China and South Korea, Confucius Ceremony Musical Dance experienced flourishing and declining together with the national fate, it is shouldering the important task to carry Dao through "dance". Although the dance performed at the Confucius ceremonies in China and South Korea is hard to find the appearance of the ancient system of the Three Generations, through the development track of Confucius Ceremony Musical Dance in the past dynasties, it is hoped that this will lay a solid theoretical foundation for the restoration of the modern Confucius Ceremony Musical Dance.

\section{REFERENCES}

[1] Origin of Chinese Characters: "Witch: Also known as Zhu. Female witch could see invisible and dance could defeat God."

[2] Reference Lim Seon-sun, "Judicial Thought of I1-moo Myung", 2011, pp. 24.

[3] (Qing) Zhang Anmao, "Li Gong Li Yue Quan Shu.Volume 16" pp. 560-561.

[4] (Song) Xu Tianlin, "Dong Han Hui Yao. Volume 5" pp. 42 Prior to this, although there are historical records of Lu Ai Gong and Han emperor sacrifice the heaven when they pass through Lu city, but it did not mention Liu Yue.

[5] (Qing) Mo Ruitang, "Wen Miao Si Dian. Volume 21" National Library Press, 2012.

[6] (Song) Xu Tianlin, "Dong Han Hui Yao. Volume 5".

[7] (Liang) Xiao Zixian, "Nan Qi Shu.Volume 9", January of Yongming three years... Shangshu ling Wang Jian discussed: "... When yuan jia institute established, Pei Song proposed that it should perform 6 rows dance, but at that time the music and dancer are not ready so the proposal is not proved, but now all things are ready so it should start to perform 6 rows dance...".

[8] (Tang) Duyou, "Tongdian. music 2", Sui Dynasty delete the music of six generations... combined Wen wu and $\mathrm{Wu}$ wu together into the eight music.

[9] (Tang) Wei Zheng, "Sui Shu. Volume 15. Chapter 10"64 dancers for Wen wu dance 64 people,wear black clothes and hats with dark red gauze dress.The dress has black cuff, black collarband,black front opening and black belt, leather boots. 16 dancers hold Yue, 16 dancer hold $\mathrm{Fu}, 16$ dancers hold Mao, 16 dancers hold $\mathrm{Yu}$, all the dancers hold Lun in their left hands.....there are 64 dancers for $\mathrm{Wu}$ wu, they wear milit ary uniform, red coat, leather belt, black boots, hold Gan in their left hands and hold Qin in their right hands.

[10] (Song) Wang Pu, "Tang Hui Yao.Volume 35", Taiwan Commercial Press, pp 637. Ceremony held in Tailao, for music use Xuanxuan and for dance use 6 row dance.

[11] (Song) Wang Pu, "Tang Hui Yao.Volume 35", Taiwan's Commercial Press.

[12] (Qing) Gu Yingtai, "Ming shi ji shi ben mo.Volume 51", Tang Kaiyuan years, the sacrifice ceremony use Jiugong music and 8 row dance. (Northern Song) Ouyang Xiu, Song Qi, Fan Zhen, Lv Xiaqing, "Xin tang shu. Volume 15," so the sacrifice ceremonies for the two capitals held in Tailao, use Gongxuan music and 6 row dance. pp. 376

[13] (Song) Wang Pu, "Tang hui yao. Volume 33," Taiwan Commercial Press.

[14] (Qing) Long Wenbin, "Ming hui yao. Volume 11", Zhonghua Book Company, 1956, pp 178. Thirteen years leap February date Dingchou, held sacrifice ceremony,first use 8 rows dance, 12 dancers for each side.

[15] (Qing) Long Wenbin, "Ming hui yao. Volume 11", Zhonghua Book Company, 1956, pp178. Nine years February, add 72 dancers for Confucius temple row dance, like the emperor system.

[16] (Qing) Long Wenbin, "Ming hui yao. Volume 11", Zhonghua Book Company, 1956, pp344. In November, correct the Confucius ceremony, music with 6 rows.

[17] (Qing) Kong Jifen, "Wen miao li qi tu shi. Volume 1", National Library Press, 2011, pp 88-89.

[18] Jeong Sun-sun, "A Comparative Study on the Present Situation of Uncertainty in the Post-Modern Times," Yong-Ryong Kang, 33, pp 270 . 